\title{
Improvement of the Enterotoxigenic Escherichia coli Infection Model for Post-Weaning Diarrhea by Controlling for Bacterial Adhesion, Pig Breed and MUC4 Genotype
}

\author{
Hiroki Matsumoto ${ }^{1, *}$, Masashi Miyagawa ${ }^{1}$, Sayaka Takahashi ${ }^{2}$, Ryouichi Shima ${ }^{3}$ \\ and Takayuki Oosumi ${ }^{1}$ \\ 1 Research and Development Section, Institute of Animal Health, JA Zen-Noh (National Federation of \\ Agricultural Cooperative Associations), 7 Ohja-machi, Sakura-shi, Chiba 285-0043, Japan; \\ miyagawa-masashi@zennoh.or.jp (M.M.); oosumi-takayuki@zennoh.or.jp (T.O.) \\ 2 Diagnostic Center, Institute of Animal Health, JA Zen-Noh (National Federation of Agricultural \\ Cooperative Associations), 7 Ohja-machi, Sakura-shi, Chiba 285-0043, Japan; takahashi-sayaka@zennoh.or.jp \\ 3 JA Zen-Noh (National Federation of Agricultural Cooperative Associations), 1-3-1 Ootemachi, Chiyoda-ku, \\ Tokyo 100-6832, Japan; shima-ryouichi@zennoh.or.jp \\ * Correspondence: matsumoto-hiroki@zennoh.or.jp; Tel.: +81-43-486-1014
}

Received: 10 June 2020; Accepted: 6 August 2020; Published: 7 August 2020

\begin{abstract}
Enterotoxigenic Escherichia coli (ETEC) is a major cause of post-weaning diarrhea (PWD) in pigs and causes significant damage to the swine industry worldwide. In recent years, there has been increased regulation against the use of antibacterial agents in swine due to their health risks. Utilizing experimental models that consistently recapitulate PWD is important for the development of non-antibacterial agents against PWD in pigs. In this study, we established a highly reproducible PWD infection model by examining differences in adhesion of ETEC to the intestinal tissue as well as the association between MUC4 polymorphisms and sensitivity to PWD. Post-weaning diarrhea differences between pig breeds were also examined. The adhesion to enterocytes varied from $10^{4.0}$ to $10^{6.4} \mathrm{CFU} / \mathrm{mL}$ even among the F4 ETEC strains. Experimental infection revealed that PWD can be induced in all MUC4 genotypes after infection with $10^{10} \mathrm{CFU} /$ pig of highly adherent ETEC, although there were variable sensitivities between the genotypes. Lowly adherent ETEC did not cause PWD as efficiently as did highly adherent ETEC. The incidence of PWD was confirmed for all pigs with the ETEC-susceptible MUC4 genotypes in all of the breeds. These results indicate that high-precision and reproducible experimental infection is possible regardless of pig breeds by controlling factors on the pig-end (MUC4 genotype) and the bacterial-end (adhesion ability).
\end{abstract}

Keywords: enterotoxigenic E. coli; post-weaning diarrhea model; pig; MUC4 genotype; experimental infection

\section{Introduction}

Post-weaning diarrhea (PWD) is most often caused by enterotoxigenic Escherichia coli (ETEC) in piglets 3-10 days after weaning. Pigs infected with ETEC typically exhibit watery diarrhea lasting one to five days, causing death by dehydration or growth deterioration in the surviving piglets and resulting in serious economic loss in the swine industry worldwide [1,2]. Enterotoxigenic E. coli that induces PWD produces heat-labile enterotoxin (LT) and/or heat-stable enterotoxin (STa and STb) and have fimbriae required to colonize intestinal cells. Enterotoxigenic E. coli exhibits mainly F4 and F18 fimbriae in pigs. Although F5, F6 and F41 fimbriae have been reported, their separation frequency 
is low [3]. While there are multiple known variants of F4 (F4ab, F4ac and F4ad) and F18 (F18ab and F18ac) fimbriae, the main variants seen in PWD are F4ac and F18ac [4,5]. The gene mucin 4 (MUC4) encodes for the F4 fimbriae receptor. The MUC4 gene has been identified on chromosome 13 [6-8]. Recently, a DNA marker-based test targeting MUC4 has become available to genotype pigs and identified single nucleotide polymorphism (SNP) (DQ848681: g.8227C > G) associated with F4ab/ac ETEC resistance and susceptibility [9]. Using this DNA marker-based test to genotype for MUC4, pigs can be categorized into the following three groups in terms of their susceptibility to ETEC-induced diarrhea: resistant (RR), susceptible heterozygote (SR) and susceptible homozygote (SS). While the incidence of diarrhea was increased by ETEC infection, sensitivity to PWD was dependent on MUC4 genotype and the occurrence of diarrhea did not reach 100\% [10,11]. As differences in MUC4 genotypes appear to affect the composition of gastrointestinal microbiota, MUC4 polymorphisms have been proposed to play roles in intestinal infection [12], such as PWD.

Antimicrobial agents have been used to control PWD. However, the emergence of antimicrobial resistance bacteria has been regarded as a global problem and has necessitated alternatives to antimicrobial agents against PWD [13-15]. Therefore, establishing a reproducible and highly efficient infection model for ETEC diarrhea using readily available pigs is important for the assessment of non-antimicrobial agents against PWD.

In this study, the ability of ETEC to adhere to enterocytes was first evaluated using various ETEC strains established in Japan. Furthermore, lowly or highly adherent ETEC strains were inoculated into pigs with different MUC4 polymorphisms, as well as into different breeds of the same MUC4 genotype. We aimed to further improve the PWD infection model by examining the frequency and degree of the resulting PWD.

\section{Materials and Methods}

\subsection{Bacterial Strains}

One hundred ETEC strains were isolated from pigs in the JA Zen-noh Diagnostic Center (Sakura, Japan). Briefly, feces from pigs were plated on 5\% sheep blood agar followed by overnight cultivation, and coliform colonies with hemolytic activity were isolated. Biochemical properties (Triple Sugar Iron (TSI) agar medium, sulfide indol motility (SIM) agar medium, indole-producing ability) were further characterized for the confirmation of E. coli. The ETEC strains were stored at $-80{ }^{\circ} \mathrm{C}$ in $10 \%$ skim milk. The strains were recultured on deoxycholate hydrogen sulfide lactose (DHL) agar at $37^{\circ} \mathrm{C}$ overnight before each experiment.

\subsection{Preparation of DNA Template and PCR Amplification}

From each strain, bacterial DNA was extracted using InstaGene Matrix (Bio-Rad Laboratories, Tokyo, Japan), followed by a check for DNA quality and purity using a NanoDrop (Thermo Scientific, Tokyo, Japan). The extracted DNA was kept at $-20^{\circ} \mathrm{C}$ until used for PCR. The PCR mixture consisted of $2 \mu \mathrm{L}$ of the DNA template, $1-\mu \mathrm{M}$ primers (Table 1), $1.25 \mathrm{U}$ Ex Taq HS (TaKaRa Bio, Inc. Kusatsu, Japan), $5 \mu \mathrm{L}$ of $10 \times$ PCR Buffer ( $\mathrm{Mg}^{2+}$ plus), $200 \mu \mathrm{M}$ of dNTP mixture and up to $50 \mu \mathrm{L}$ of distilled water. After activation at $94^{\circ} \mathrm{C}$ for $2 \mathrm{~min}$, the reactions were subjected to 30 cycles of amplification consisting of a $30 \mathrm{~s}$ denaturation at $94{ }^{\circ} \mathrm{C}, 30 \mathrm{~s}$ annealing at $55^{\circ} \mathrm{C}, 60 \mathrm{~s}$ extension at $72{ }^{\circ} \mathrm{C}$ and a final extension step at $72{ }^{\circ} \mathrm{C}$ for $10 \mathrm{~min}$. For detection of the PCR products, amplified DNA samples were examined by electrophoresis in a $2 \%$ agarose gel and visualized with ethidium bromide under UV light. 
Table 1. Primers used in this study.

\begin{tabular}{|c|c|c|c|}
\hline Target Gene & Primer Sequence $\left(5^{\prime}\right.$ to $\left.3^{\prime}\right)$ & Product Size (bp) & Reference \\
\hline $\mathrm{F} 4$ & $\begin{array}{l}\text { F:GGTGATTTCAATGGTTCGGTC } \\
\text { R:ATTGCTACGTTCAGCGGAGCG }\end{array}$ & 704 & [16] \\
\hline F5 & $\begin{array}{l}\text { F:TGCGACTACCAATGCTTCTG } \\
\text { R:TATCCACCATTAGACGGAGC }\end{array}$ & 450 & [16] \\
\hline F6 & $\begin{array}{l}\text { F:TCTGCTCTTAAAGCTACTGG } \\
\text { R:AACTCCACCGTTTGTATCAG }\end{array}$ & 333 & [16] \\
\hline F18 & $\begin{array}{l}\text { F:GTGAAAAGACTAGTGTTTATTTC } \\
\text { R:CTTGTAAGTAACCGCGTAAGC }\end{array}$ & 510 & [17] \\
\hline F41 & $\begin{array}{l}\text { F:GAGGGACTTTCATCTTTTAG } \\
\text { R:AGTCCATTCCATTTATAGGC }\end{array}$ & 431 & [16] \\
\hline LT & $\begin{array}{l}\text { F:ATTTACGGCGTTACTATCCTC } \\
\text { R:TTTTGGTCTCGGTCAGATATG }\end{array}$ & 280 & [16] \\
\hline STa & $\begin{array}{l}\text { F:TCCGTGAAACAACATGACGG } \\
\text { R:ATAACATCCAGCACAGGCAG }\end{array}$ & 244 & [16] \\
\hline $\mathrm{STb}$ & $\begin{array}{l}\text { F:GCCTATGCATCTACACAATC } \\
\text { R:TGAGAAATGGACAATGTCCG }\end{array}$ & 278 & [16] \\
\hline muc4 & $\begin{array}{l}\text { F:GTGCCTTGGGTGAGAGGTTA } \\
\text { R:CACTCTGCCGTTCTCTTTCC }\end{array}$ & 367 & [9] \\
\hline
\end{tabular}

\subsection{Animals}

All animal studies were performed at the JA Zen-noh Institute of Animal Health after being approved by the Animal Experimental Review Committee (ethical approval code No. 324 and 366). WL (large white $\times$ Landrace), LW (Landrace $\times$ large white), LL (Landrace $\times$ Landrace), WW (large white $\times$ large white) and LWD (Landrace $\times$ large white $\times$ Duroc) pigs were originated from specific pathogen-free herds. All pigs were transported into the Zen-noh Institute of Animal Health at day of weaning (21 day of age) and housed in individual pens. Body weights were measured at 21 day of age, autopsy or death. Pigs were fed a standard diet of approximately $400 \mathrm{~g}$ per day and were provided water ab libitum via push drinker.

\subsection{Porcine Intestinal Epitheliocyte (PIE) Cell Line}

Porcine intestinal epitheliocyte cells are non-transformed intestinal cultured cells originally derived from intestinal epithelia isolated from an unsuckled neonatal swine [17]. Porcine intestinal epitheliocyte cells were maintained in antibiotic free Dulbecco's modified Eagle's medium (DMEM, High Glucose, Pyruvate) (Gibco, Tokyo, Japan) supplemented with 10\% fetal bovine serum (FBS) at $37^{\circ} \mathrm{C}$ in $5 \% \mathrm{CO}_{2}$.

\subsection{Bacterial Adherence Assays}

Porcine intestinal epitheliocyte cells were cultured in 6-well plates (approximately $5 \times 10^{5}$ cells $/$ well) to confluence. Each ETEC strain was grown in Luria-Bertani (LB) medium for $6 \mathrm{~h}$ at $37^{\circ} \mathrm{C}$ and harvested. After centrifugation, the cells were washed three times in sterile phosphate buffered saline (PBS). Adherence assays were performed by inoculating $\sim 1 \times 10^{7} \mathrm{CFU} / \mathrm{mL}$ of each ETEC on a confluent PIE cell monolayer. The plates were incubated for $1 \mathrm{~h}$ at $37^{\circ} \mathrm{C}$ in $5 \% \mathrm{CO}_{2}$. The monolayers were then washed with PBS, trypsinized and disrupted by repeated pipetting. Serial dilutions of the cell lysates were plated onto deoxycholate hydrogen sulfide lactose (DHL) agar plates and incubated overnight at $37^{\circ} \mathrm{C}$ for bacterial enumeration.

\subsection{DNA Marker-Based Test}

Piglets were tested for their sensitivity against the F4ab/ac fimbriae of E. coli by a genetic marker test for MUC4 [9]. Tails samples were taken from the piglets shortly after farrowing, and genomic DNA was extracted using the QIAamp DNA Minikit (QIAGEN, Tokyo, Japan) according to the 
manufacturer's instructions. The PCR mixture consisted of $1 \mu \mathrm{L}$ of DNA template, $0.1-\mu \mathrm{M}$ primers (Table 1), 0.5 U Ex Taq HS (TaKaRa Bio, Inc., Shiga, Japancity), $2.5 \mu \mathrm{L}$ of $10 \times$ PCR Buffer $\left(\mathrm{Mg}^{2+}\right.$ plus), $200 \mu \mathrm{M}$ of dNTP mixture and water up to $25 \mu \mathrm{L}$. After activation at $95^{\circ} \mathrm{C}$ for $15 \mathrm{~min}$, the reactions were subjected to 35 cycles of amplification consisting of a 15 -s denaturation at $95^{\circ} \mathrm{C}, 30 \mathrm{~s}$ annealing at $60{ }^{\circ} \mathrm{C}$, $30 \mathrm{~s}$ extension at $72{ }^{\circ} \mathrm{C}$ and a final extension step at $72{ }^{\circ} \mathrm{C}$ for $10 \mathrm{~min}$. Touchdown PCR was performed, whereby the annealing temperature was decreased by $1^{\circ} \mathrm{C}$ per cycle in the first 10 cycles, starting at $60^{\circ} \mathrm{C}$. The last 25 cycles were performed at an annealing temperature of $50^{\circ} \mathrm{C}$. The amplified DNA was digested with $\mathrm{XbaI}$ (TaKaRa Bio, Inc., Shiga, Japancity) at $37^{\circ} \mathrm{C}$ for $2 \mathrm{~h}$ for restriction fragment length polymorphism (RFLP) analysis. The samples for RFLP analysis were examined by electrophoresis in a $2 \%$ agarose gel and visualized with ethidium bromide under UV light. The resistant allele (R) is indigestible by XbaI (367 base pairs), whereas the susceptible allele (S) is digested into two fragments (151 and 216 base pairs). The resulting genotypes will be henceforth referred to as SS (151 and 216 base pairs), SR (151, 216 and 367 base pairs) or RR (367 base pairs).

\subsection{Bacterial Culture and Infection}

From the results of the cell adhesion test, highly and lowly adherent (HA, LA) ETEC strains were selected and used as challenge strains. Artificial rifampicin resistance of these strains was induced via successive cultivation in DHL agar containing up to $100 \mu \mathrm{g} / \mathrm{mL}$ of rifampicin (RifDHL). These ETEC strains were grown in LB medium for $6 \mathrm{~h}$ at $37^{\circ} \mathrm{C}$, harvested by centrifugation and were resuspended with $10 \%$ skim milk. A total of 28 male pigs (WL) were assigned into 6 experimental groups based on their MUC4 genotypes. They were orally challenged with the indicated amount of ETEC with a single dose at 22 days of age (Group 1: HA-ETEC, $10^{10} \mathrm{CFU}$ per pig, SS genotype, $n=4$; Group 2: HA-ETEC, $10^{10}$ CFU per pig, RS, $n=8$; Group 3: HA-ETEC, $10^{10}$ CFU per pig, RR, $n=4$; Group 4: HA-ETEC, $10^{8}$ CFU per pig, RS, $n=4$; Group 5: LA-ETEC, $10^{10}$ CFU per pig, SS, $n=4$; Group 6: LA-ETEC, $10^{10} \mathrm{CFU}$ per pig, RS, $\left.n=4\right)$. In another set of experiments, only the HA-ETEC strain was utilized in male RS pigs (WL, $n=5 ; \mathrm{LW}, n=5 ; \mathrm{LL}, n=12 ; \mathrm{WW}, n=10 ; \mathrm{LWD}, n=5$ ). They were orally challenged by ETEC with a single dose of approximately $10^{10} \mathrm{CFU}$ per pig at 22 days of age. At 7 days after infection, pigs were euthanized using sodium pentobarbital under sedation with xylazine and midazolam for both infection experiments.

\subsection{Diarrhea Evaluation}

The feces of the pigs were observed individually every morning. Fecal properties were measured as follows: 0 (normal), 1 (soft feces), 2 (semi-liquid) and 3 (liquid). The diarrhea incidence indicates the percentage of individuals exhibiting a score of 1 or more in each group. The duration of diarrhea was recorded individually, and the mean duration for the group was calculated. Mortality rate throughout the monitoring period was recorded.

\subsection{Bacterial Shedding}

Samples were collected from pigs using rectal swabs and were suspended in $1 \mathrm{~mL}$ sterile physiological saline at 1,3,5, 7 days post infection (dpi). The samples were serially diluted in sterile physiological saline, plated on RifDHL and incubated for $24 \mathrm{~h}$ at $37^{\circ} \mathrm{C}$. Colonies that grew on agar plates were directly counted.

\subsection{Statistical Analyses}

The mean fecal score was analyzed with repeated-measures ANOVA, with days post infection as a within subject factor and test groups as the between-subject, adjusting for pairwise comparisons by Bonferroni test. In terms of the incidence of diarrhea, pigs with a fecal score of 1 or more during the experimental period were considered to have diarrhea. The incidence of diarrhea and mortality were analyzed using Fisher's exact test for each test group. Statistical analyses were performed using Excel 2016 (Microsoft Corporation, Washington, WA, USA) with the add-in software Statcel 4. A $p$-value of 
less than 0.05 was considered to be significantly different between groups. Results are presented as means $\pm \mathrm{SE}$, except the mortality rate.

\section{Results}

\subsection{Detection of Fimbriae and Enterotoxins Genes}

Of the 100 strains used in this study, 83 strains expressed the F4 fimbriae gene, 13 strains expressed the F18 fimbriae gene, and 4 strains (F_UT) did not express any genes corresponding to F4/F5/F6/F18/F41 fimbriae (Table 2). Furthermore, the strains carrying the F4 fimbriae gene also had almost all of the LT, STa and STb genes.

Table 2. Presence of adhesion factor and enterotoxin genes in E. coli from pigs in Japan.

\begin{tabular}{ccccc}
\hline \multirow{2}{*}{ Fimbriae Gene } & \multicolumn{4}{c}{ Enterotoxin Genes } \\
& LT & Sta & STb & Number of Strains \\
\hline \multirow{2}{*}{ F4 } & + & + & + & 77 \\
& + & - & + & 6 \\
\multirow{2}{*}{ F18 } & + & + & + & 9 \\
& + & + & - & 3 \\
\multirow{2}{*}{ F_UT } & + & - & - & 1 \\
& + & + & + & 3 \\
\hline
\end{tabular}

F_UT: Strains that do not express any fimbrial genes for F4, F5, F6, F18, F41.

\subsection{Bacterial Cell Adhesion Test}

Among the strains having the F4 fimbriae gene, many were confirmed to be highly adherent (10 6 CFU/mL or more) (Table 3). On the other hand, some F4 fimbriae strains had low adherence capacity of less than $10^{5} \mathrm{CFU} / \mathrm{mL}$. It was observed that the F18 fimbriae and the F_UT strains exhibited low adherence capacities of $10^{5} \mathrm{CFU} / \mathrm{mL}$ or less. For the infection tests, highly adherent bacteria (adherence of $10^{6.1} \mathrm{CFU} / \mathrm{mL}, \mathrm{F} 4+, \mathrm{LT}+, \mathrm{STa}+, \mathrm{STb}+$ strains) and lowly adherent bacteria (adherence of $10^{4.0} \mathrm{CFU} / \mathrm{mL}, \mathrm{F} 4+, \mathrm{LT}+, \mathrm{STa}+, \mathrm{STb}+$ ) were individually selected.

Table 3. Identification of adhesion ability to PIE cells.

\begin{tabular}{ccc}
\hline Fimbriae Gene & $\begin{array}{c}\text { Range of Bacterial Adherence } \\
\left(\log _{\mathbf{1 0}} \text { CFU/mL) }\right.\end{array}$ & Number of Strains \\
\hline \multirow{2}{*}{ F4 } & $6.0-6.4$ & 17 \\
& $5.0-5.9$ & 51 \\
\multirow{2}{*}{ F18 } & $4.0-4.9$ & 9 \\
& $4.0-4.9$ & 5 \\
F_UT & $3.0-3.9$ & 4 \\
& $4.0-4.9$ & 2 \\
\hline
\end{tabular}

3.3. Susceptibility to PWD in Pigs with Different MUC4 Genotypes Inoculated with Differentially Adherent F4 ETEC Strains

WL Pigs with different MUC4 genotypes were inoculated with a single oral dose of ETEC 2 days after weaning. The mean fecal score was high at 1-3 dpi, and diarrhea was observed. Regardless of the degree of adhesion abilities of the strains, at 4-7 dpi, the surviving pigs tended to recover (Table 4). SS-genotyped pigs showed the most severe diarrheal symptoms (mean fecal score 2.00) in the group infected with highly adherent bacteria and challenged with $10^{10} \mathrm{CFU} / \mathrm{pig}$, and the incidence of diarrhea was $100 \%$. RS-genotyped pigs showed no significant differences in fecal score (1.83), incidence of diarrhea (100\%) and diarrhea duration (3.4 days) compared to SS-genotyped pigs. On the other hand, 
the mean fecal score of the RR-genotyped pigs at 1-3 dpi was 0.25 , significantly lower than that of SSand RS-genotyped pigs, and the incidence of diarrhea was only $25 \%$. In the group infected with highly adherent bacteria and challenged with $10^{8} \mathrm{CFU} /$ pig, even RS-genotyped pigs had a low fecal score of 0.50 , and the incidence of diarrhea was only $50 \%$. In the group infected with lowly adherent bacteria and challenged with $10^{10} \mathrm{CFU} / \mathrm{pig}$, SS- and RS-genotyped pigs had low fecal scores of 1.22 and 0.50, respectively, and the diarrheal incidence rate was only $50 \%$.

The number of bacteria shedding during the test period is shown in Figure 1. In SS pigs infected with highly adherent bacteria and challenged with $10^{10} \mathrm{CFU} / \mathrm{pig}$, the average bacterial shedding count of $10^{7} \mathrm{CFU} /$ rectal swab and the high shedding continued to 5 dpi. RS pigs infected with highly and lowly adherent bacteria and challenged with $10^{10} \mathrm{CFU} /$ pig showed $10^{6}$ to $10^{7} \mathrm{CFU} /$ rectal swab and bacterial shedding up to $5 \mathrm{dpi}$. In all test groups, bacteria were shed at $10^{4} \mathrm{CFU} /$ rectal swab or less by 7 dpi.

Table 4. Evaluation of diarrhea in experimental infections comparing high and low adhesion ETEC and MUC4 genotypes. Data are presented mean \pm SE.

\begin{tabular}{|c|c|c|c|c|c|c|}
\hline \multirow{4}{*}{$\begin{array}{c}\text { Challenged Strains } \\
\text { Infectious Bacterial Load (CFU/pig) } \\
\text { Pig's Genotyped of MUC4 } \\
n\end{array}$} & \multicolumn{4}{|c|}{ HAEC ${ }^{(1)}$} & \multirow{2}{*}{\multicolumn{2}{|c|}{ LAEC $^{(2)}$}} \\
\hline & \multicolumn{3}{|c|}{$10^{10}$} & \multirow{2}{*}{$\begin{array}{l}10^{8} \\
\text { RS }\end{array}$} & & \\
\hline & SS & RS & $\mathbf{R} \mathbf{R}$ & & SS & RS \\
\hline & 4 & 8 & 4 & 4 & 4 & 4 \\
\hline \multicolumn{7}{|l|}{ Mean body weight $(\mathrm{kg})$} \\
\hline Initial & $6.93 \pm 0.49$ & $6.51 \pm 0.51$ & $5.88 \pm 0.13$ & $6.00 \pm 0.64$ & $5.93 \pm 0.47$ & $6.30 \pm 0.48$ \\
\hline Final $^{(3)}$ & $6.75 \pm 0.43$ & $6.88 \pm 0.54$ & $6.75 \pm 0.32$ & $7.13 \pm 0.72$ & $6.25 \pm 0.78$ & $7.00 \pm 0.54$ \\
\hline Average daily gain (g) & $-21.9 \pm 16.4$ & $19.3 \pm 54.8$ & $109.4 \pm 29.9$ & $140.6 \pm 12.9$ & $-53.1 \pm 188.8$ & $87.5 \pm 38.5$ \\
\hline \multicolumn{7}{|l|}{ Mean fecal score } \\
\hline $1-3$ dpi & $2.00 \pm 0.28^{a, b, c}$ & $1.83 \pm 0.25 \mathrm{~d}, \mathrm{e}, \mathrm{f}$ & $0.25 \pm 0.18^{\mathrm{a}, \mathrm{d}}$ & $0.50 \pm 0.29 \mathrm{~b}, \mathrm{e}$ & $1.22 \pm 0.43$ & $0.50 \pm 0.29^{\mathrm{c}, \mathrm{f}}$ \\
\hline $4-7 \mathrm{dpi}$ & $0.88 \pm 0.27$ & $0.43 \pm 0.14$ & 0 & $0.38 \pm 0.20^{a}$ & $0.25 \pm 0.25$ & 0 \\
\hline \multicolumn{7}{|l|}{ Diarrhea incidence (\%) } \\
\hline $1-3$ dpi & 100 & $100 \mathrm{~g}$ & $25 \mathrm{~g}$ & 50 & 50 & 50 \\
\hline $4-7 \mathrm{dpi}$ & 75 & $71.4^{\mathrm{h}, \mathrm{i}}$ & $0^{\mathrm{h}}$ & 25 & 50 & $0^{\mathrm{i}}$ \\
\hline Duration of diarrhea (day) & $4.8 \pm 0.9$ & $3.4 \pm 0.7$ & $0.5 \pm 0.5$ & $1.5 \pm 01.2$ & $2.0 \pm 2.0$ & $0.8 \pm 0.5$ \\
\hline Mortality $(\%)$ & 0 & 12.5 & 0 & 0 & 50 & 0 \\
\hline
\end{tabular}

(1) Highly adherent E. coli. (2) Lowly adherent E. coli. (3) Measured at necropsy (7 dpi) or death. ( $\left.{ }^{a-i}\right)$ Same superscripts indicate significant differences between two groups $(p<0.05)$.

\subsection{Differences in Susceptibility to PWD in Various RS-Type Pig Breeds Inoculated with Highly Adherent} F4 ETEC

We next evaluated the differences in PWD sensitivity among different pig breeds with the RS genotype. A single oral administration of the HA (highly adherent) strain to 22-day-old RS pigs (WL, LW, LL, WW and LWD breeds) after weaning caused diarrhea (with the mean fecal scores at 1-3 dpi: 2.76 for LL, 2.75 for LWD and 2.47 for WW) (Table 5). Mean fecal scores for WL and LW were 1.82 and 1.50 , respectively and were significantly lower than those of LL and LWD. In addition, the mean fecal scores at 4-7 dpi indicated that diarrhea in LL was more likely to occur than in other breeds. LL and LWD had similar mean fecal scores, but differences in mortality were noted. LL mortality was $75 \%$ and LWD was only $20 \%$.

Figure 2 shows the number of bacterial shedding during the test period. The LL breed, which exhibited the highest mean fecal score and mortality rate, showed bacterial shedding of $10^{8} \mathrm{CFU} /$ rectal swab at 1-3 dpi. For the other breeds, no difference was found in the number of bacterial shedding. 


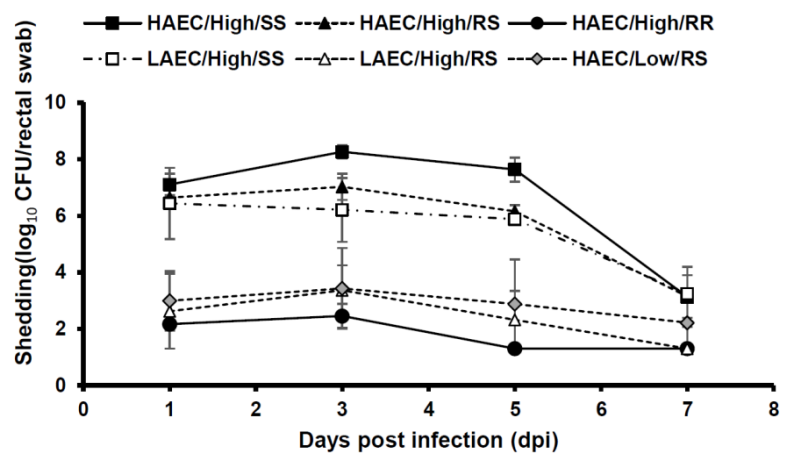

Figure 1. Mean F4 enterotoxigenic Escherichia coli (ETEC) shedding per rectal swab in experimental infections after oral challenge comparing highly and lowly adhering strains and MUC4 genotypes. HEC and LEC indicate highly and lowly adherent Escherichia coli, respectively. High or Low indicates the amount of ETEC used to orally challenge the pigs (high-approximately $10^{10} \mathrm{CFU} / \mathrm{pig}$; low-approximately $10^{8} \mathrm{CFU} / \mathrm{pig}$ ). SS/RS/RR indicate the MUC4 genotype of the pigs utilized. The detection limit was $200 \mathrm{CFU} /$ rectal swab. Error bars, Standard error.

Table 5. Evaluation of diarrhea in experimental infections challenged with Highly adherent E. coli comparing breeds with the MUC4 RS genotype. Data are presented mean \pm SE.

\begin{tabular}{|c|c|c|c|c|c|}
\hline $\begin{array}{c}\text { Pigs Breed }^{(1)} \\
n\end{array}$ & $\begin{array}{c}\text { WL } \\
5\end{array}$ & $\begin{array}{c}\text { LW } \\
5\end{array}$ & $\begin{array}{l}\text { LL } \\
12\end{array}$ & $\begin{array}{c}\text { WW } \\
10\end{array}$ & $\begin{array}{c}\text { LWD } \\
5\end{array}$ \\
\hline \multicolumn{6}{|l|}{ Mean body weight $(\mathrm{kg})$} \\
\hline Initial & $6.44 \pm 0.22$ & $6.34 \pm 0.20$ & $6.03 \pm 0.25$ & $6.44 \pm 0.36$ & $6.66 \pm 0.22$ \\
\hline Final $^{(2)}$ & $6.70 \pm 0.41$ & $6.70 \pm 0.25$ & $5.67 \pm 0.31$ & $6.30 \pm 0.37$ & $6.60 \pm 0.24$ \\
\hline Average daily gain (g) & $-25.8 \pm 94.7$ & $45.0 \pm 20.0$ & $-150.0 \pm 54.1$ & $-20.2 \pm 29.8$ & $-19.5 \pm 43.0$ \\
\hline \multicolumn{6}{|l|}{ Mean fecal score } \\
\hline $1-3 \mathrm{dpi}$ & $1.82 \pm 0.26^{\mathrm{a}, \mathrm{b}}$ & $1.50 \pm 0.24^{\mathrm{c}, \mathrm{d}}$ & $2.76 \pm 0.09^{a, c}$ & $2.47 \pm 0.12^{\mathrm{d}}$ & $2.75 \pm 0.26^{b}$ \\
\hline $4-7 \mathrm{dpi}$ & $0.25 \pm 0.13^{\mathrm{e} 1}$ & $0.25 \pm 0.12^{\mathrm{f} 1}$ & $1.58 \pm 0.34^{e, f, g}$ & $0.71 \pm 0.17 \mathrm{~g}$ & $1.00 \pm 0.27^{\mathrm{b}}$ \\
\hline \multicolumn{6}{|l|}{ Diarrhea incidence (\%) } \\
\hline $1-3 \mathrm{dpi}$ & 100 & 100 & 100 & 100 & 100 \\
\hline $4-7 \mathrm{dpi}$ & 33.3 & 40.0 & 100 & 80.0 & 100 \\
\hline Duration of diarrhea (day) & $4.0 \pm 1.0$ & $3.8 \pm 0.6$ & $5.0 \pm 0.6$ & $4.3 \pm 0.3$ & $5.5 \pm 1.0$ \\
\hline Mortality $(\%)$ & 40.0 & 0 & 75.0 & 10.0 & 20.0 \\
\hline
\end{tabular}

(1) WL:Large White $\times$ Landrace; LW:Landrace $\times$ Large White; LL:Landrace $\times$ Landrace; and WW:Large White $\times$ Large White; LWD:Landrace $\times$ Large White $\times$ Duroc. ${ }^{(2)}$ Measured at necropsy $\left(7\right.$ dpi) or deat.h. $\left.{ }^{\left({ }^{-}-g\right.}\right)$ Same superscripts indicate significant differences between two groups $(p<0.05)$.

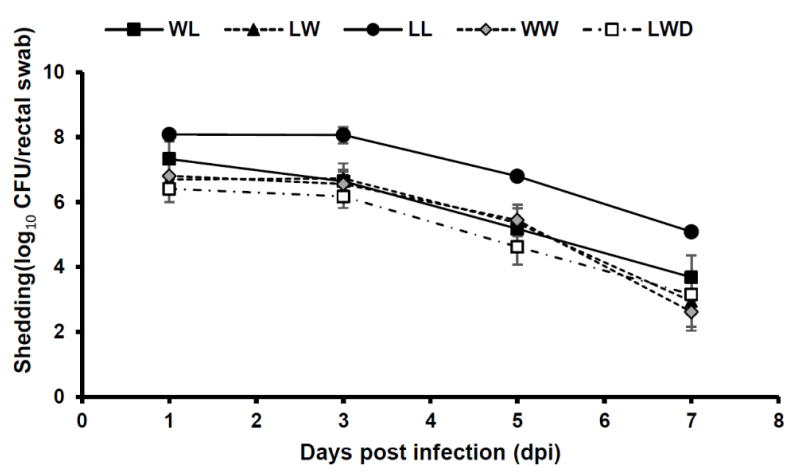

Figure 2. Mean F4 ETEC shedding per rectal swab in experimental infections after oral challenge comparing pig breeds with MUC4 RS genotype. RS pigs [WL (large white $\times$ Landrace), LW (Landrace $\times$ large white), LL (Landrace $\times$ Landrace), WW (large white $\times$ large white) and LWD (Landrace $\times$ large white $\times$ Duroc)] were orally challenged with a single dose of ETEC (approximately $10^{10} \mathrm{CFU} / \mathrm{pig}$ ). The amount of bacterial shedding was evaluated during the test period. Detection limit was $200 \mathrm{CFU} /$ rectal swab. Error bars, Standard error. 


\section{Discussion}

In this study, we characterized the properties of 100 ETEC strains according to their fimbriae (F4, F5, F6, F18, F41) and enterotoxin (LT, STa, STb) gene expression. Among the strains examined, the strain carrying the F4 fimbrial gene was the most common (83/100; 83\%) in the examined strains. According to other reports, many E. coli strains isolated from pigs express $\mathrm{F} 4$ as an adhesion gene, which is consistent with the present result [18-20]. However, Matsuda et al. and Jin et al. previously reported the rate of presence of the F4 fimbriae gene as $45.8 \%$ and $51.2 \%$, respectively $[19,20]$. These differences may be due to the fact that our study targeted strains without the stx2e gene. On the other hand, strains carrying both the F4 and F18 genes were reported in a previous study [21]. Similar to previous studies [18-20], E. coli harboring the F4 gene was shown to be one of the major causes of PWD in this study. Furthermore, E. coli carrying all of the enterotoxin genes (LT, STa, STb) regardless of the fimbriae genes was mainly detected. It is still unclear the contribution of each individual enterotoxin strain to PWD; however, it is believed that all strains can cause diarrhea [22-24]. Therefore, we examined cell adhesion ability in strains carrying all toxin genes.

We found that F4 ETEC strains in general exhibit high adhesion ability $\left(10^{6} \mathrm{CFU} / \mathrm{mL}\right)$ (Table 3$)$. However, some of these strains also have a low adhesion ability $\left(10^{4.0}\right.$ to $\left.10^{4.9} \mathrm{CFU} / \mathrm{mL}\right)$. This suggests that even ETECs with the same F4 gene had different adhering ability depending on the strain. In F18 ETEC strains, none exhibited high attachment ability. One possibility is that the F18 receptor may not be sufficiently expressed during the neonatal period, as PIE cells used in this test were established from newborn pigs $[3,25,26]$. Therefore, to evaluate the ability of F18 ETEC to adhere to cells, it will be important to utilize other experimental paradigms in future studies. In this study, we selected highly and lowly adherent strains in F4 ETEC and tested whether in vitro strain selection affects the experimental infection test.

In SS type pigs infected with 1010 CFU/pig of highly adherent ETEC, severe diarrhea (watery stool) was observed at 1-3 dpi, but not at 4-7 dpi (Table 4). However, the onset of diarrhea (score 1 or more) was 4.8 days, the same as previous reports [27]. In this study, we presumed that changes in fecal properties appear significantly at $1-3 \mathrm{dpi}$, and we focused on fecal scores for this 1-3 dpi period thereafter. Similar to previous reports $[10,11]$, in the group infected with highly adherent bacteria and $10^{10} \mathrm{CFU} / \mathrm{pig}$, it was shown that the sensitivity to F4 E. coli differs depending on the MUC4 genotype: 2.00 for SS pigs, 1.83 for RS pigs and 0.25 for RR pigs. In the group infected with highly adherent bacteria and $10^{8} \mathrm{CFU} / \mathrm{pig}$, the average fecal score of RS pigs was as low as 0.50 , indicating that the number of bacteria was also an important factor. On the other hand, in the group infected with low adherence bacteria and $10^{10} \mathrm{CFU} / \mathrm{pig}$, the incidence of diarrhea was clearly reduced, compared with the group infected with highly adherent bacteria and $10^{10} \mathrm{CFU} /$ pig: 1.22 in SS pigs and 0.50 in RS pigs. These results indicate that it is very important to consider the adherence in selecting a challenging strain. Experimental infection studies suggested that a pig infection model for PWD could be established by infecting $10^{10} \mathrm{CFU} /$ pig with highly adherent ETEC using SS or RS pigs (Table 4).

We evaluated the differences in PWD sensitivity among pig breeds with the RS genotype (Table 5 and Figure 2). WL pigs with the RS genotype were used in two independent infection experiments (Tables 4 and 5), and their mean fecal scores at 1-3 dpi were 1.82 and 1.82, respectively, indicating high reproducibility. There were significant differences in the degree of diarrhea and marked differences in mortality among the breeds (Table 5). LL showed the highest diarrhea score (2.76), and a high mortality rate (75\%). LWD and WW showed high fecal scores of 2.75 and 2.47 , respectively. However, mortality rates of LWD and WW were lower ( $20 \%$ and $10 \%$, respectively) than LL. These results suggest that the differences among breeds may influence their susceptibility to F4 ETEC even if they have the same MUC4 genotype. It has been reported that the susceptibility to F4 ETEC is affected not only by the MUC4 genotype, but also by other factors such as MUC13 polymorphism, which may have contributed to differences in diarrhea and mortality among breeds [16,28]. Moreover, there have been reports that susceptibility to other diseases differ among breeds such the reproductive and respiratory syndrome virus, porcine circovirus type $2[29,30]$. However, in this study, we successfully induced 
diarrhea in all WL pigs carrying the RS and SS genes and in all pig breeds carrying the RS gene, albeit with varying degrees of diarrhea. Therefore, with this development of a highly accurate PWD infection model, we recommend the use of pigs with the MUC4 gene (RS or SS) infected with $10^{10} \mathrm{CFU} / \mathrm{pig}$ with highly adherent ETEC.

\section{Conclusions}

It is clear that high-precision and reproducible experimental infection is possible regardless of pig breeds by controlling factors on the pig-end (MUC4 genotype) and factors on the bacterial-end (adhesion ability). We believe that this study has further improved the accuracy of the PWD infection model. Our PWD infection model makes possible the development and evaluation of preventive agents against PWD without increasing the number of experimental animals.

Author Contributions: Conceptualization, H.M., R.S.; formal analysis, H.M.; investigation, H.M., M.M.; resources, S.T.; writing, H.M.; project administration, T.O. All authors have read and agreed to the published version of the manuscript.

Funding: This research received no external funding.

Acknowledgments: The authors thank the technicians who assisted with the animal experiments in this study. We also thank Masahumi Mukomoto and Jun Nakamura of Osaka Prefecture University for their advice in manuscript preparation.

Conflicts of Interest: The authors declare no conflicts of interest.

\section{References}

1. Dubreuil, J.D.; Isaacson, R.E.; Schifferli, D.M. Animal Enterotoxigenic Escherichia coli. EcoSal Plus $2016,7$. [CrossRef]

2. Cox, E.; Loos, M.; Coddens, A.; Devriendt, B.; Melkebeek, V.; Vanrompay, D.; Goddeeris, B.M. Post-Weaning E. coli Infections in Pigs and Importance of the Immune System; Actes des Journées AFMVP: Maisons-Alfort, France, 2012.

3. Fairbrother, J.M.; Nadeau, É.; Gyles, C.L. Escherichia coli in postweaning diarrhea in pigs: An update on bacterial types, pathogenesis, and prevention strategies. Anim. Health. Res. Rev. 2005, 6, 17-39. [CrossRef]

4. Alexa, P.; Štouračová, K.; Hamřík, J.; Rychlík, I. Gene typing of the colonisation factors K88 (F4) in enterotoxigenic Escherichia coli strains isolated from diarrhoeic piglets. Vet. Med. 2001, 46, 46-49. [CrossRef]

5. Cheng, D.; Sun, H.; Xu, J.; Gao, S. Prevalence of fimbial colonization factors F18ab and F18ac in Escherichia coli isolates from weaned piglets with edema and/or diarrhea in China. Vet. Microbiol. 2005, 110, 35-39. [CrossRef]

6. Fontanesi, L.; Bertolini, F.; Dall'Olio, S.; Buttazzoni, L.; Gallo, M.; Russo, V. Analysis of Association between the MUC4 g.8227C>G Polymorphism and Production Traits in Italian Heavy Pigs Using a Selective Genotyping Approach. Anim. Biotechnol. 2012, 23, 147-155. [CrossRef] [PubMed]

7. Samantha, O.S.; Danica, J.E.; Josephine, P.M.; Julie, C.S.; Sahibzada, S.A.; Mark, O.; David, W.M.; Jae, C.K.; John, R.P. Effect of mucin 4 allele on susceptibility to experimental infection with enterotoxigenic F4 Escherichia coli in pigs fed experimental diets. J. Anim. Sci. Biotechnol. 2019, 10, 56. [CrossRef]

8. Sterndale, S.O.; Miller, D.W.; Mansfield, J.P.; Kim, J.C.; Pluske, J.R. Technical note: Novel delivery methods for an enterotoxigenic Escherichia coli infection model in MUC4-locus sequenced weaner pigs. J. Anim. Sci. 2019, 97, 4503-4508. [CrossRef] [PubMed]

9. Jørgensen, C.B.; Cirera, S.; Archibald, A.; Andersson, L.; Fredholm, M.; Edfors-Lilia, I. Porcine Polymorphisms and Methods for Detecting Them. U.S. Patent 20,060,275,763A1, 15 July 2004.

10. Jensen, G.M.; Frydendahl, K.; Svendsen, O.; Jørgensen, C.B.; Cirera, S.; Fredholm, M.; Nielsen, J.P.; Møller, K. Experimental infection with Escherichia coli O149:F4ac in weaned piglets. Vet. Microbiol. 2006, 115, 243-249. [CrossRef] 
11. Roubos-van den Hil, P.J.; Litjens, R.; Oudshoorn, A.-K.; Resink, J.W.; Smits, C.H.M. New perspectives to the enterotoxigenic E. coli $\mathrm{F} 4$ porcine infection model: Susceptibility genotypes in relation to performance, diarrhoea and bacterial shedding. Vet. Microbiol. 2017, 202, 58-63. [CrossRef]

12. Luise, D.; Motta, V.; Bertocchi, M.; Salvarani, C.; Clavenzani, P.; Fanelli, F.; Pagotto, U.; Bosi, P.; Trevisi, P. Effect of Mucine 4 and Fucosyltransferase 1 genetic variants on gut homoeostasis of growing healthy pigs. J. Anim. Physiol. Anim. Nutr. 2019, 103, 801-812. [CrossRef]

13. Luppi, A.; Bonilauri, P.; Dottori, M.; Gherpelli, Y.; Biasi, G.; Merialdi, G.; Maioli, G.; Martelli, P. Antimicrobial Resistance of F4+ Escherichia coli Isolated from Swine in Italy. Transbound. Emerg. Dis. 2015, 62, 67-71. [CrossRef] [PubMed]

14. Abraham, S.; Jordan, D.; Wong, H.S.; Johnson, J.R.; Toleman, M.A.; Wakeham, D.L.; Gordon, D.M.; Turnidge, J.D.; Mollinger, J.L.; Gibson, J.S.; et al. First detection of extended-spectrum cephalosporin- and fluoroquinolone-resistant Escherichia coli in Australian food-producing animals. J. Glob. Antimicrob. Resist. 2015, 3, 273-277. [CrossRef] [PubMed]

15. Abraham, S.; Trott, D.J.; Jordan, D.; Gordon, D.M.; Groves, M.D.; Fairbrother, J.M.; Smith, M.G.; Zhang, R.; Chapman, T.A. Phylogenetic and molecular insights into the evolution of multidrug-resistant porcine enterotoxigenic Escherichia coli in Australia. Int. J. Antimicrob. Agents 2014, 44, 105-111. [CrossRef] [PubMed]

16. Sinha, R.; Sahoo, N.R.; Kumar, P.; Qureshi, S.; Kumar, A.; Ravikumar, G.V.P.P.S.; Bhushana, B. Comparative jejunal expression of MUC 13 in Indian native pigs differentially adhesive to diarrhoeagenic E. coli. J. Appl. Anim. Res. 2018, 46, 107-111. [CrossRef]

17. Moue, M.; Tohno, M.; Shimazu, T.; Kido, T.; Aso, H.; Saito, T.; Kitazawa, H. Toll-like receptor 4 and cytokine expression involved in functional immune response in an originally established porcine intestinal epitheliocyte cell line. Biochim. Biophys. Acta 2008, 1780, 134-144. [CrossRef]

18. Ikwap, K.; Larsson, J.; Jacobson, M.; Owiny, D.O.; Nasinyama, G.W.; Nabukenya, I.; Mattsson, S.; Aspan, A.; Erume, J. Prevalence of adhesin and toxin genes in E. coli strains isolated from diarrheic and non-diarrheic pigs from smallholder herds in northern and eastern Uganda. BMC Microbiol. 2016, 16, 178. [CrossRef]

19. Katsuda, K.; Kohmoto, M.; Kawashima, K.; Tsunemitsu, H. Frequency of enteropathogen detection in suckling and weaned pigs with diarrhea in Japan. J. Vet. Diagn. Investig. 2006, 18, 350-354. [CrossRef]

20. Hur, J.; Lee, K.; Lee, J. Age-dependent competition of porcine enterotoxigenic E. coli (ETEC) with different fimbria genes-Short communication. Acta Vet. Hung. 2011, 59, 411-417. [CrossRef]

21. Luppi, A.; Gibellini, M.; Gin, T.; Vangroenweghe, F.; Vandenbroucke, V.; Bauerfeind, R.; Bonilauri, P.; Labarque, G.; Hidalgo, Á. Prevalence of virulence factors in enterotoxigenic Escherichia coli isolated from pigs with post-weaning diarrhoea in Europe. Porc. Heal. Manag. 2016, 2, 20. [CrossRef]

22. Zhang, C.; Rausch, D.; Zhang, W. Little heterogeneity among genes encoding heat-labile and heat-stable toxins of enterotoxigenic Escherichia coli strains isolated from diarrheal pigs. Appl. Environ. Microbiol. 2009, 75, 6402-6405. [CrossRef]

23. Zhang, W.; Berberov, E.M.; Freeling, J.; He, D.; Moxley, R.A.; Francis, D.H. Significance of heat-stable and heat-labile enterotoxins in porcine colibacillosis in an additive model for pathogenicity studies. Infect. Immun. 2006, 74, 3107-3114. [CrossRef] [PubMed]

24. Nair, G.B.; Takeda, Y. The heat-stable enterotoxins. Microb. Pathog. 1998, 24, 123-131. [CrossRef] [PubMed]

25. Nagy, B.; Casey, T.A.; Whipp, S.C.; Moon, H.W. Susceptibility of porcine intestine to pilus-mediated adhesion by some isolates of piliated enterotoxigenic Escherichia coli increases with age. Infect. Immun. 1992, 60, 1285-1294. [CrossRef] [PubMed]

26. Fairbrother, J.M.; Nadeau, É. Colibacillosis. In Diseases of Swine; Zimmerman, J.J., Karriker, L.A., Ramirez, A., Schwartz, K.J., Stevenson, G.W., Zhang, J., Eds.; John Wiley \& Sons, Inc.: Hoboken, NJ, USA, 2019; pp. 807-834.

27. Kaevska, M.; Lorencova, A.; Videnska, P.; Sedlar, K.; Provaznik, I.; Trckova, M. Effect of sodium humate and zinc oxide used in prophylaxis of post-weaning diarrhoea on faecal microbiota composition in weaned piglets. Vet. Med. 2016, 61, 328-336. [CrossRef]

28. Goetstouwers, T.; Van Poucke, M.; Coppieters, W.; Nguyen, V.U.; Melkebeek, V.; Coddens, A.; Van Steendam, K.; Deforce, D.; Cox, E.; Peelman, L.J. Refined candidate region for F4ab/ac enterotoxigenic Escherichia coli susceptibility situated proximal to MUC13 in pigs. PLoS ONE 2014, 9, e105013. [CrossRef] 
29. Opriessnig, T.; Patterson, A.R.; Madson, D.M.; Pal, N.; Rothschild, M.; Kuhar, D.; Lunney, J.K.; Juhan, N.M.; Meng, X.J.; Halbur, P.G. Difference in severity of porcine circovirus type two-induced pathological lesions between Landrace and Pietrain pigs. J. Anim. Sci. 2009, 87, 1582-1590. [CrossRef]

30. Liang, W.; Ji, L.; Zhang, Y.; Zhen, Y.; Zhang, Q.; Xu, X.; Liu, B. Transcriptome differences in Porcine Alveolar Macrophages from Tongcheng and large white pigs in response to highly pathogenic porcine reproductive and respiratory syndrome virus (PRRSV) infection. Int. J. Mol. Sci. 2017, 18, 1475. [CrossRef]

(c)

(C) 2020 by the authors. Licensee MDPI, Basel, Switzerland. This article is an open access article distributed under the terms and conditions of the Creative Commons Attribution (CC BY) license (http://creativecommons.org/licenses/by/4.0/). 